\title{
EKPERIMENTASI MODEL PEMBELAJARAN KOOPERATIF TIPE TSTS dan TPS TERHADAP KEMAMPUAN PEMECAHAN MASALAH MATEMATIKA SISWA KELAS XI
}

\author{
Lisa Yuni Astuti ${ }^{1}$, Sutriyono ${ }^{2}$, Fika Widya Pratama ${ }^{3}$ \\ 1,2,3 Universitas Kristen Satya Wacana Salatiga, Jl. Diponegoro No.52-60, Salatiga, Sidorejo \\ Lisayuniastuti19@gmail.com
}

\begin{abstract}
This study aims to determine whether there are differences in the application of TSTS and TPS learning models to mathematical problem solving abilities. This type of research is a quasi-experimental. The subjects of this study are students of XI MIPA 1 students (26 students) and XI MIPA 2 (27 students) in SMA Negeri 2 Salatiga 2 in the academic year 2018/2019 school year and the sampling technique used Cluster Random Sampling. This experiment used the design of the Randomized Control Group Pretest-Posttest Design to measure initial ability and final ability after being given different treatments. The final ability analysis using the Independent sample ttest with a significance level of $5 \%$ obtained a significance value of 0.007 (less than 0.05 ). It can be concluded there are significant differences in the rstudents' mathematics problem solving abilities result. TPS is seen from the average value of class XI MIPA 1 (84.00 higher than the average value of class XI MIPA 2 (73.0769).
\end{abstract}

Keywords: TSTS, TPS, Mathematical Problem Solving Ability

\begin{abstract}
Abstrak
Penelitian ini bertujuan untuk mengetahui ada tidaknya perbedaan penerapan model pembelajaran TSTS dan TPS terhadap kemampuan pemecahan masalah matematika. Jenis penelitian ini adalah eksperimen semu. Subjek penelitian ini siswa kelas XI MIPA 1 (26 siswa) dan XI MIPA 2 (27 siswa) di SMA Negeri 2 Salatiga tahun ajaran 2018/2019 dan teknik pengambilan sampel menggunakan Cluster Random Sampling. Eksperimen ini menggunakan desain The Randomized Control Group Pretest-Posttest Desain untuk mengukur kemampuan awal dan kemampuan akhir setelah diberikan perlakuan yang berbeda. Analisis kemampuan akhir dengan menggunakan uji Independent sample t-test dengan taraf signifikansi 5\% diperoleh nilai signifikansi 0.007 (kurang dari 0.05 ) maka dapat disimpulkan bahwa terdapat perbedaan dari hasil kemampuan pemecahan masalah matematika siswa dapat disimpulkan pula jika model pembelajaran TSTS lebih baik dari model pembelajaran TPS dilihat dari nilai rata-rata kelas XI MIPA 1 (84.00 lebih tinggi dari nilai rata-rata kelas XI MIPA 2 (73.0769).
\end{abstract}

Kata Kunci: TSTS, TPS, Kemampuan Pemecahan Masalah Matematika

Menurut Permendiknas no 22 tahun 2006 mata pelajaran matematika harus diberikan kepada semua peserta didik dimulai dari sekolah dasar untuk dibekali kemampuan berpikir logis, kritis, analisis, kreatif dan kemampuan bekerjasama serta mengembangkan kemampuan menggunakan matematika dakam memecahkan masalah. Tujuan pembelajaran matematika menurut Depdiknas tahun 2006 (dalam Saepuloh: 2013) salah satunya adalah memecahkan masalah yang meliputi kemampuan memahani masalah, merancang model matematika, menyelesaikan model dan menafsirkan solusi matematika. Berdasarkan tujuan matematika terlihat bahwa salah satu tujuan matematika adalah siswa memiliki kemampuan dalam memecahkan masalah matematika. Menurut Hujodo (2005: 129) pemecahan masalah merupakan proses penerimaan masalah sebagai tantangan untuk menyelesaikan masalah dimana dalam matematika berbentuk soal latihan. Pemecahan masalah amat penting dalam matematika Rusefendi (Efendi, 2012) pemecahan masalah bukan saja bagi mereka 
yang dikemudian hari akan mendalami atau mempelajari matematika, melainkan juga bagi mereka yang akan menerapkannya dalam bidang studi lain dalam kehidupan sehari-hari. Dengan demikian pemecahan masalah sangat penting dalam matematika sebagai tantangan untuk menyelesaiakan masalah.

Diperlukan pembelajaran kooperatif yang dapat memberikan kesempatan bagi siswa untuk memperoleh pengalaman dalam memecahkan masalah matematika. Salah satu pembelajaran kooperatif adalah model pembelajaran Two Stay Two Stray (TSTS) dan Think Pair Share (TPS). Dalam proses pembelajaran TSTS dan TPS pada tahap diskusi siswa diharapkan dapat memecahkan atau menyelesaikan masalah yang diberikan oleh guru (Huda, 2011). Model pembelajaran TSTS memberikan kesempatan kepada kelompok untuk membagikan hasil dan informasi dengan kelompok lain serta model pembelajaran ini dapat diterapkan untuk semua mata pelajaran dan semua tingkatan umur (Huda, 2011). TSTS bertujuan agar peserta didik bertanggung jawab, saling membantu menyelesaikan masalah dan mendorong peserta bertanya, mencari informasi, menjelaskan, menyimak penjelasan antar peserta didik. Model pembelajaran TSTS melatih peserta didik bersosialisasi dengan yang lain. Pembelajaran kooperatif tipe TSTS adalah salah satu tipe atau model pembelajaran kooperatif yang mudah diterapkan yang melibatkan aktivitas seluruh peserta didik dan melibatkan peran aktif peserta didik.

Menurut Suprijono (2009: 93), pembelajaran dengan metode TSTS diawali dengan pembagian kelompok. Setelah kelompok terbentuk guru memberikan tugas berupa permasalahan-permasalahan yang harus mereka diskusikan jawabannya. Setelah diskusi intrakelompok usai, dua orang dari masing-masing kelompok meninggalkan kelompoknya untuk bertamu kepada kelompok yang lain. Anggota kelompok yang tidak mendapat tugas sebagai tamu (stray) mempunyai kewajiban menerima tamu (stay) dari kelompok lain. Tugas penerima tamu adalah menyajikan hasil kerja kelompoknya kepada tamu tersebut. Dua orang yang bertugas sebagai tamu diwajibkan bertamu kepada semua kelompok. Jika mereka telah usai menyelesaikan tugasnya, mereka kembali ke kelompoknya masingmasing. Setelah kembali ke kelompok asal, baik peserta didik yang bertugas bertamu maupun mereka yang bertugas menerima tamu mencocokkan dan membahas hasil kerja yang telah mereka dapatkan dari kelompok lain.

Selain model pembelajaran TSTS, pembelajaran kooperatif lainnya adalah model Think Pair Share (TPS). Huda (2011: 136-137) TPS merupakan pembelajaran yang memungkinkan siswa untuk bekerja sendiri dan bekerja sama dengan siswa lain serta dapat mengoptimalkan partisipasi siswa. Menurut Huda (2011) model pembelajaran TPS diawali dengan siswa dikelompokkan yang setiap kelompok beranggotakan empat siswa. Guru memberikan tugas pada setiap kelompok yang masingmasing anggota kelompok memikirkan dan mengerjakan tugas yang diberikan guru sendiri-sendiri terlebih dahulu. Kelompok membentuk anggota-anggotanya secara berpasangan dimana setiap pasangan mendiskusikan hasil pekerjaan individunya. Kedua pasangan lalu bertemu kembali dalam kelompoknya masing-masing untuk menshare hasil diskusinya. 
Model pembelajaran kooperatif tipe TSTS dan TPS merupakan pembelajaran yang memberikan kesempatan pada siswa untuk memecahkan masalah dengan cara berkelompok dimana dalam pembagian kelompok terdiri dari 4-5 siswa. Perbedaan model pembelajaran kooperatif tipe TSTS dan TPS terletak pada proses pemecahan masalah jika model TSTS siswa dalam pembagian tugas dibagi menjadi 2 yaitu 2 siswa yang stay dan 2 siswa yang stray yang diharuskan 2 siswa yang bertugas sebagai stray diwajibkan bertamu kepada semua kelompok. Jika mereka telah usai menyelesaikan tugasnya, mereka kembali ke kelompoknya masing-masing sedangkan, model pembelajaran siswa berpikir secara individu terlebih dahulu yang kemudian akan berpasangan untuk berdiskusi memecahkan masalah lalu anggota kelompok kembali dalam kelompoknya masing-masing untuk menshare hasil diskusinya. Model pembelajaran TSTS dan TPS dapat merangsang dan mendorong siswa untuk memecahkan masalah dan mengembangkan kemampuan pemecahan masalah (dalam Subandi dkk: 2014)

Terdapat beberapa penelitian yang telah meneliti model pembelajaran TSTS antara lain, 1) Penelitian Junaryadi (2012) dalam pembelajaran matematika kelas IX SMP meneliti pengaruh model pembelajaran TSTS terhadap kemampuan koneksi matematis. Hasil penelitian Junryadi menunjukkan bahwa model pembelajaran TSTS dapat meningkatkan kemampuan koneksi matematis; 2) penelitian Saraswati dkk (2012) dalam pembelajaran matematika kelas VIII SMP meneliti pengaruh penerapan model pembelajaran TSTS terhadap minat dan kemampuan pemahanan konsep. Hasil penelitian Saraswati dkk menunjukkan bahwa penerapan model pembelajaran TSTS dapat meningkatkan minat dan kemapuan pemahanan konsep; 3) Habibi (2014) dalam pembelajaran Teknik Elektronika kelas X SMK meneliti pengaruh model pembelajaan terhadap hasil belajar. Hasil penelitian tersebut menunjukkan bahwa model pembelajaran TSTS lebih baik dibandingkan model pembelajaran langsung; 4) adapula penelitian yang meneliti model TSTS yang telah dilakukan oleh Suraji dan Sari (2017) dalam pembelajaran Matematika bagi siswa kelas V SD Berdasarkan hasil penelitian Suraji disimpulkan bahwa penerapan model kooperatif tipe TSTS dapat meningkatkan kemampuan pemecahan masalah matematis siswa kelas V SD.

Selain penelitian model pembelajaran TSTS terdapat pula penelitian yang telah meneliti model pembelajaran TPS antara lain, 1) Ni'mah dan Dwijananti (2014) dalam pembelajaran IPA kelas VIII MTS meneliti pengaruh model pembelajaran TPS tehadap hasil belajar dan aktivitas belajar. Penelitian ini menunjukkan bahwa dengan penerapan model pembelajaran TPS dapat meningkatkan hasil belajar; 2) penelitian Husna dkk (2013) meneliti pembelajaran matematika siswa kelas VIII MTS. Hasil penelitian Husna dkk menunjukkan bahwa model pembelajaran TPS dapat meningkatkan kemampuan pemecahan masalah dan komunikasi matematis.

Berdasarkan teori dan hasil penelitian tentang model pembelajaran yang berorientasi pada kemampuan pemecahan masalah, maka dalam penelitian ini akan menerapkan pembelajaran berbasis masalah pada model pembelajaran kooperatif tipe TSTS dan TPS guna untuk mengetahui ada tidaknya 
perbedaan penerapan model pembelajaran TSTS dan TPS terhadap kemampuan pemecahan masalah matematika siswa kelas XI. Selain itu, diharapkan penelitian ini dapat dijadikan referensi model pembelajaran bagi guru dan memberikan gambaran penerapan model pembelajaran yang berorientasi pada pemecahan masalah dalam pembelajaran matematika.

\section{METODE PENELITIAN}

Penelitian ini merupakan penelitian eksperimen semu. Penelitian ini menggunakan desain The Randomized Control Group Pretest-Posttest Desain. Populasi penelitian ini adalah seluruh siswa kelas XI MIPA SMA Negeri 2 Salatiga tahun ajaran 2018/2019 dan teknik pengambilan sampel menggunakan Cluster Random Sampling dimana diambil 2 kelas secara random XI MIPA 1 (kelas eksperimen 1) dan XI MIPA 2 (kelas eksperimen 2) sebagai subjek penelitian. Kelas XI MIPA 1 diberikan perlakuan dengan model pembelajaran kooperatif tipe Two Stay Two Stray (TSTS) sedangkan kelas XI MIPA 2 diberikan perlakuan dengan model pembelajaran kooperatif tipe Think Pair Share (TPS). Penelitian dilakukan pada tanggal 21 Maret 2019- 12 April 2019 dengan pengumpulan data menggunakan teknik observasi, tes, dan dokumentasi. Durasi pembelajaran untuk kelas XI MIPA 1 (TSTS) dan kelas XI MIPA2 (TPS) adalah 4 jam dalam satu minggu, yang mana dibagi dalam 2 kali pertemuan dengan masing-masing alokasi pembelajaran 245 menit dengan jumlah alokasi waktu seluruhnya 8 menit ( 4 pertemuan). sebelum dilakukan penelitian terlebih dahulu peneliti mengajukan validasi RPP dan LKS (Lembar Kerja Siswa) dengan materi Integral Tak Tentu kepada dosen pendidikan matematika dan satu guru matematika pada sekolah tersebut.

Analisis data peneliti menggunakan alat bantu SPSS 16 dan untuk analisis kemampuan pemecahanan masalah peneliti menggunakan pedoman penskoran menurut Sumaryanta yang dapat dilihat dari tabel 1.

\section{Tabel 1}

Pendoman Penskoran Pemecahan Masalah Matematika

\begin{tabular}{|l|l|l|lr|}
\multicolumn{1}{|c|}{ Kriteria } & \multicolumn{2}{|c|}{0} & \multicolumn{2}{|c|}{$\mathbf{1}$} \\
\hline Memahami masalah & $\begin{array}{l}\text { Tidak memahami } \\
\text { masalah }\end{array}$ & $\begin{array}{l}\text { Kurang memahami } \\
\text { masalah }\end{array}$ & $\begin{array}{l}\text { Mampu memahami } \\
\text { masalah }\end{array}$ \\
\hline $\begin{array}{l}\text { Merumuskan } \\
\text { pemecahan masalah }\end{array}$ & $\begin{array}{l}\text { Tidak mampu } \\
\text { merumuskan } \\
\text { pemecahan }\end{array}$ & $\begin{array}{l}\text { Mampu merumuskan } \\
\text { pemecahan, tetapi tidak } \\
\text { tepat }\end{array}$ & $\begin{array}{l}\text { Mampu merumuskan } \\
\text { pemecahanan dengan } \\
\text { tepat }\end{array}$ \\
\hline $\begin{array}{l}\text { Melaksanakan } \\
\text { pemecahan masalah }\end{array}$ & $\begin{array}{l}\text { Tidak mampu } \\
\text { melaksanakan } \\
\text { pemecahan masalah }\end{array}$ & $\begin{array}{l}\text { Mampu melaksanakan } \\
\text { pemecahan masalah, } \\
\text { tetapi tidak tepat }\end{array}$ & $\begin{array}{l}\text { Mampu melaksanakan } \\
\text { pemecahan masalah }\end{array}$ \\
\hline $\begin{array}{l}\text { Membuat } \\
\text { kesimpulan }\end{array}$ & $\begin{array}{l}\text { Tidak mampu } \\
\text { membuat kesimpulan }\end{array}$ & $\begin{array}{l}\text { Mampu membuat } \\
\text { kesimpulan, tetapi tidak } \\
\text { tepat }\end{array}$ & $\begin{array}{l}\text { Mampu membuat } \\
\text { kesimpulan }\end{array}$ \\
\hline
\end{tabular}




\section{HASIL DAN PEMBAHASAN}

\section{Kondisi Kemampuan Awal}

\section{Deskripsi kondisi awal kedua kelas (sebelum diberikan perlakuan)}

Data deskripsi kondisi siswa bertujuan untuk mengetahui kemampuan awal kedua kelas yang akan diteliti sebelum diberikannya perlakuan yang berbeda. Data kondisi awal diperoleh dari nilai ulangan semester genap tahun ajaran 2018/2019 matematika siswa kelas XIMIPA 1 dan XI MIPA 2 di SMA Negeri 2 salatiga yang mana kedua kelas memiliki jumlah siswa yang sama yaitu 26 siswa. Hasil analisis deskripsi awal dapat dilihat dari Tabel 2.

\section{Tabel 2}

Hasil Analisis Kondisi Kemampuan Awal

\begin{tabular}{lrrrr}
\hline & N & Minimum & Maximum & \multicolumn{1}{c}{ Mean } \\
\hline XI MIPA 1 (TSTS) & 26 & 47.00 & 89.00 & 64.8462 \\
\hline XI MIPA 2 (TPS) & 26 & 35.00 & 87.00 & 69.4231 \\
\hline Valid N (listwise) & 26 & & &
\end{tabular}

Berdasarkan Tabel 2 dapat diketahui bahwa nilai minimum, dan maksimum kelas XI MIPA 1 secara berturut turut adalah 47.00 dan 89.00 sedangkan kelas XI MIPA 2 adalah 35.00 dan 87.00 dengan demikian, menunjukkan untuk nilai minimum dan maksimum XI MIPA 1 lebih tinggi dari kelas XI MIPA 2. Dilihat dari nilai rata-rata maka nilai rata-rata kelas XI MIPA 2 (64.8462) lebih tinggi dari pada kelas XI MIPA 1 (69.4231). Pada nilai standar deviasi kelas XI MIPA 1(12.06878) lebih tinggi daripada nilai standar deviasi XI MIPA 2 (10.86342). hal ini menunjukkan bahwa kelas XI MIPA 1 jarak setiap titik individu dekat dari nilai rata-rata kata lain homogen.

\section{Uji normalitas dan uji beda rerata kondisi kemampuan awal}

Uji beda rerata bertujuan untuk mengetahui seimbang atau tidaknya kemampuan kondisi awal kedua kelas. Syarat uji beda rerata adalah uji normalitas dan uji homogenitas dengan menggunakan nilai signifikansi sebesar 5\%. Uji beda rerata menggunakan alat bantu SPSS 16. Uji normalitas disajikan pada Tabel 3.

Tabel 3

Hasil Uji Normalitas

\begin{tabular}{lcccccr}
\hline & \multicolumn{2}{c}{ Kolmogorov-Smirnov $^{\mathrm{a}}$} & \multicolumn{2}{c}{ Shapiro-Wilk } \\
\hline & Statistic & $\mathrm{df}$ & \multicolumn{1}{c}{ Sig. } & Statistic & df \\
\hline XI MIPA 1 (TSTS) & .160 & 26 & .086 & .937 & 26 \\
\hline XI MIPA 2 (TPS) & .123 & 26 & $.200^{*}$ & .913 & 26 \\
\hline
\end{tabular}

a. Lilliefors Significance Correction

*. This is a lower bound of the true significance.

Uji normalitas dengan shapiro wilk menunjukkan nilai signifikansi kelas XI MIPA 1 sebesar 0.112 yang berarti nilai signifikansi lebih dari 0.05 sehingga dapat disimpulkan bahwa data kemampuan siswa kelas XI MIPA 1 berasal dari populasi yang berdistribusi normal. Nilai signifikansi kelas XI MIPA 2 sebesar 0.031 yang berarti nilai signifikansi kurang dari 0.05 dengan demikian dapat 
disimpulkan bahwa data kemampuan siswa kelas XI MIPA 2 tidak berasal dari populasi yang berdistribusi normal sehingga uji beda rerata menggunakan uji nonparametik. Hasil uji nonparametik digunakan dengan uji mann whitney $U$. Analisis uji mann whitney $U$ menunjukkan nilai signifikansi sebesar 0.70 yang berarti nilai signifikansi lebih dari 0.05 dengan demikian dapat disimpulkan bahwa tidak terdapat perbedaan data kemampuan awal kedua kelas kata lain siswa kelas XI MIPA 1 dan siswa kelas XI MIPA mempunyai kemampuan yang sama atau seimbang.

\section{Proses Pelaksanaan Pembelajaran}

Pelaksanaan pembelajaran dilakukan di SMA Negeri 2 Salatiga yang dilakukan pada tanggal 21 Maret 2019 -12 April 2019. Durasi pembelajaran untuk kelas XI MIPA 1 (TSTS) dan kelas XI MIPA2 (TPS) adalah 4 jam dalam satu minggu, yang mana dibagi dalam 2 kali pertemuan dengan masingmasing alokasi pembelajaran 2 selama 45 menit dengan jumlah alokasi waktu seluruhnya 8 menit (4 pertemuan).

\section{Proses Pembelajaran dengan Menerapkan Model Pembelajaran Kooperatif Tipe Two Stay Two Stray (TSTS)}

Proses pembelajaran dengan menerapkan model pembelajaran kooperatif tipe TSTS dilakukan pada tanggal 25 April 2019-12 April 2019 dengan jumlah alokasi waktu 4 pertemuan. Kegiatan pendahuluan di kelas dengan model ini diawali dengan guru menyapa dan menyiapkan psikis siswa agar lebih siap memulai pembelajaran dengan menyiapkan peralatan yang diperlukan saat pembelajaran.. Pada pertemuan pertama siswa diberikan suatu tanyangan video tentang perlunya solidaritas dalam berkelompok dan siswa diberikan penjelasan mengenai manfaat belajar materi integral dalam kehidupan sehari-hari. Proses pembelajaran siswa dibagi dalam kelompok yang mana dari pertemuan pertama sampai ketiga siswa belajar melalaui berkelompok. Pada pertemuan kedua dan ketiga siswa diajak mengingat materi pada pertemuan sebelumnya namun, pada pertemuan ketiga siswa kembali diberikan penjelasan mengenai manfaat belajar integral dalam kehidupan sehari-hari. Siswa dalam proses pembelajaran dibagi menjadi kelompok yang terdiri dari $4-5$ siswa. Pembagian tugas dalam kelompok dibagi menjadi 2 yaitu 2 anggota menjadi stay dan 2 anggota menjadi stray.Pembagian kelompok digunakan selama 3 kali pertemuan.

Pada kegiatan inti siswa diberikan lembar kerja siswa (LKS) yang berbeda setiap kelompoknya. LKS yang diberikan didiskusikan terlebih dahulu oleh setiap kelompok untuk memecahkan masalah pada LKS sebelum anggota kelompok yang bertugas Stray berpindah kekelompok lain. Setiap sesi perpindahan siswa diberikan waktu selama 10 menit (5 menit pertama anggota Stay menjelaskan materi dan berdiskusi terlebih dahulu lalu bergantian bagi anggota Stray). Anggota kelompok yang bertugas Stray kembali pada kelompok asal yang mana dalam kelompok asal akan berdiskusi kembali tentang materi yang telah didapatkan.

Kegiatan penutup pertemuan pertama sampai ketiga sama yaitu siswa diminta perwakilan dari dua kelompok untuk mempresentasikan hasil diskusi kedepan dan sekaligus juga guru bersama- 
sama siswa menyimpulkan materi yang didapat dalam pertemuan. Sebelum akhir pembelajaran guru menyampaikan pada pertemuan keempat diadakan penilaian ulangan harian.

\section{Proses Pembelajaran dengan Menerapkan Model Pembelajaran Kooperatif Tipe Think Pair Share}

Proses pembelajaran dengan menerapkan model pembelajaran kooperatif tipe TPS dilakukan pada tanggal 21 April 2019-11 April 2019 dengan jumlah alokasi waktu 4 pertemuan. Pada kegiatan pendahuluan kelas dengan model pembelajaran ini sama halnya dengan kegiatan pendahuluan kelas dengan model pembelajaran TSTS yaitu diawali dengan guru menyapa dan menyiapkan psikis siswa agar lebih siap memulai pembelajaran. Pada pertemuan pertama siswa diberikan suatu tanyangan video tentang perlunya solidaritas dalam berkelompok dan siswa diberikan penjelasan mengenai manfaat belajar materi integral dalam kehidupan sehari-hari. Pada pertemuan kedua dan ketiga siswa diajak mengingat materi pada pertemuan sebelumnya namun, pada pertemuan ketiga siswa kembali diberikan penjelasan mengenai manfaat belajar integral dalam kehidupan sehari-hari. Siswa dalam proses pembelajaran dibagi menjadi kelompok yang terdiri dari $4-5$ siswa yang mana dari pertemuan pertama sampai ketiga siswa belajar melalui berkelompok dengan anggota kelompok sama.

Pada kegiatan inti siswa diberikan LKS yang mana setiap kelompok mendapatkan LKS yang sama. Pada kegiatan ini berbeda dari kegiatan inti dengan menggunakan model pembelajaran TSTS yaitu pada kegiatan inti dengan model pembelajaran TPS siswa memecahkan masalah pada LKS secara bertahap dari sub bab TPS 1 sampai selesai. Aturan dalam model pembelajaran TPS siswa mengerjakan sub bab TPS 1 secara individu terlebih dahulu kemudian setelah berpikir individu siswa berpasanngan dengan temannya dalam satu kelompok untuk berdiskusi untuk memecahkan masalah pada LKS yang setelahnya siswa secara berkelompok berdiskusi dan mengerjakan soal yang ada pada LKS.

Kegiatan penutup penerapan TPS sama halnya dengan TSTS yaitu pertemuan pertama sampai ketiga sama yaitu siswa diminta perwakilan dari dua kelompok untuk mempresentasikan hasil diskusi kedepan dan sekaligus juga guru bersama-sama siswa menyimpulkan materi yang didapat dalam pertemuan. Sebelum akhir pembelajaran guru menyampaikan pada pertemuan keempat diadakan penilaian ulangan harian.

\section{Deskripsi Data Kemampuan Akhir}

\section{Deskripsi Kemampuan Pemecahan Masalah Matematika Kedua Kelas (setelah diberikan perlakuan)}

Data hasil kemampuan pemecahan masalah melalui posttest yang dilakukan siswa kelas XI MIPA 1 dan XI MIPA2 setelah diberikan perlakuan yang berbeda. Siswa kelas XI MIPA1 diberikan perlakuan dengan model pembelajaran kooperatif tipe Two Stay Two Stray (TSTS) sedangkan Siswa kelas XI MIPA2 diberikan perlakuan dengan model pembelajaran kooperatif tipe Think Pair Share (TPS). Deskripsi Kemampuan pemecahan masalah matematika kedua kelas dengan menggunakan alat 
bantu hitung SPSS 16. Hasil deskripsi kemampuan pemecahan masalah matematika kedua kelas dapat dilihat dari Tabel 4.

\section{Tabel 4}

Hasil Deskripsi Kemampuan Pemecahan Masalah Matematika

\begin{tabular}{|c|c|c|c|c|}
\hline & $\mathrm{N}$ & Minimum & Maximum & Mean \\
\hline XI MIPA 1 (TSTS) & 26 & 65.00 & 100.00 & 84.0000 \\
\hline XI MIPA 2 (TPS) & 26 & 38.00 & 100.00 & 73.0769 \\
\hline
\end{tabular}

Berdasarkan Tabel 4 dapat diketahui bahwa nilai minimum kelas TSTS sebesar 65.00 yang mana nilai tersebut lebih besar dari nilai minimum kelas TPS yakni sebesar 38.00 namun, terlihat dari nilai maksimum kedua kelas memiliki nilai maksimum sama besar yaitu 100. Rata-rata kelas TSTS dan kelas TPS secara berturut-turut sebesar 84.00; 73.0769. Terlihat bahwa nilai rata-rata kelas TSTS lebih tinggi dari kelas TPS sedangkan dari nilai standar deviasi menunjukkan jika nilai yang diperoleh kelas TSTS(10.53755) lebih rendah dari nilai standar deviasi kelas TPS(16.53342). hal ini menunjukkan bahwa kelas TSTS jarak setiap individu dekat dengan nilai rata-rata.

\section{Uji Normalitas Dan Uji Beda Rerata Kondisi Kemampuan Pemecahan Masalah Matematika Kedua Kelas}

Uji normalitas kedua kelas menggunakan uji normalitas shapiro wilk dengan taraf signifikansi sebesar 5\%. Hasil uji normalitas diperoleh menggunakan alat bantu SPSS 16 yang disajikan pada Tabel 5 .

Tabel 5

Hasil Uji Normalitas Kemapuan Pemecahan Masalah Matematika

\begin{tabular}{lcccccr}
\hline & \multicolumn{3}{c}{ Kolmogorov-Smirnov $^{\mathrm{a}}$} & \multicolumn{2}{c}{ Shapiro-Wilk } \\
\hline & Statistic & $\mathrm{df}$ & & Sig. & Statistic & df \\
\hline XI MIPA 1 (TSTS) & .109 & 26 & $.200^{*}$ & .958 & 26 \\
\hline XI MIPA 2 (TPS) & .111 & 26 & $.200^{*}$ & .966 & 26 \\
\hline
\end{tabular}

a. Lilliefors Significance Correction

*. This is a lower bound of the true significance.

Pada tabel di atas terlihat bahwa nilai signifikansi kelas TSTS sebesar 0.355 dan nilai signifikansi kelas TPS sebesar 0.515. Kedua kelas sama-sama memiliki nilai signifikansi yang lebih dari 0.05 . Hal ini berarti bahwa kedua kelas berasal dari populasi yang berdistribusi normal. Oleh karena itu uji beda rerata menggunakan uji parametik yaitu uji Independent sample t-test. Berikut hasil uji Independent sample t-test disajikan pada Tabel 6. 


\section{Tabel 6}

Hasil Uji Independent sample t-test

\section{Levene's Test for}

Equality of

Variances

t-test for Equality of Means

$95 \%$
Confiden

ce

Interval

Std. of the

Mean Error Differenc

\begin{tabular}{|c|c|c|c|c|c|c|c|c|c|}
\hline & & $\mathrm{F}$ & Sig. & $\mathrm{t}$ & $\mathrm{df}$ & $\begin{array}{l}\text { Sig. (2- } \\
\text { tailed) }\end{array}$ & $\begin{array}{c}\text { Differenc } \\
\mathrm{e}\end{array}$ & $\begin{array}{c}\text { Differenc } \\
\mathrm{e}\end{array}$ & $\frac{\mathrm{e}}{\text { Lower }}$ \\
\hline \multirow[t]{2}{*}{$\begin{array}{l}\text { Nilai } \\
\text { gabungan }\end{array}$} & $\begin{array}{l}\text { Equal variances } \\
\text { assumed }\end{array}$ & 4.816 & .033 & 2.841 & 50 & .006 & 10.92308 & 3.84505 & 3.20007 \\
\hline & $\begin{array}{l}\text { Equal variances } \\
\text { not assumed }\end{array}$ & & & 2.841 & $\begin{array}{r}42.43 \\
4\end{array}$ & .007 & 10.92308 & 3.84505 & 3.16581 \\
\hline
\end{tabular}

Tabel 6 menunjukkan hasil homogenitas melalui uji Levene's dimana diperoleh nilai signifikansi sebesar 0.033 yang berarti nilai signifikansi kurang dari 0.05 hal ini menunjukkan bahwa kedua kelas tidak berasal dari populasi yang homogen. Oleh karena itu digunakan uji Independent sample t-test jenis Equal variances not assumed yang menghasilkan nilai signifikansi sebesar 0.007 dimana nilai signifikansi tersebut kurang dari 0.05 maka dapat disimpulkan bahwa terdapat perbedaan antara penerapan model pembelajaran kooperatif tipe TSTS dan TPS terhadap hasil kemampuan pemecahan masalah matematika siswa dan dapat disimpulkan pula jika model pembelajaran TSTS lebih baik dari model pembelajaran TPS dilihat dari nilai rata-rata kelas XI MIPA 1 lebih tinggi dari nilai rata-rata kelas XI MIPA 2.

\section{KESIMPULAN}

Berdasarkan penelitian yang telah dilakukan dengan memberikan perlakuan yang berbeda dari kelas XI MIPA 1 (menggunakan model pembelajaran TSTS) dan kelas XI MIPA 2 (menggunakan model pembelajaran TPS) dapat disimpulkan terdapat perbedaan penerapan model pembelajaran TSTS dan TPS terhadap kemampuan pemecahan masalah matematika. dengan hasil uji beda rerata dengan menggunkanan uji Independent sample t-test diperoleh nilai signifikansi sebesar 0.007 (kurang dari 0.05) dan dapat disimpulkan pula jika model pembelajaran TSTS lebih baik dari model pembelajaran TPS dilihat dari nilai rata-rata kelas XI MIPA 1 lebih tinggi dari nilai rata-rata kelas XI MIPA 2. 


\section{DAFTAR PUSTAKA}

Huda, Miftahul. 2011. Cooperative Learning Metode, Teknik, Struktur dan Model Terapan. Yogyakarta: Pustaka Pelajar

Slavin, E Robert. 2005. Cooperative Learning Teori dan Riset. Bandung: Penerbit Nusa Dua

Suprijono, Agus. 2009. Cooperative Learning Teori dan Aplikasi PAIKEM. Yogyakarta: Pustaka Pelajar

Taryadi, A. 1989. Epistemologi Pemecahan Masalah. Jakarta: Gramedia

Hudojo, Herman. 2005. Pengembangan Kurikulum dan Pembelajaran Matematika. Malang: Universitas Negeri Malang (UM PRESS)

Sugiyono. 2014. Statistika untuk Penelitian. Bandung: Alfabeta

Husna, dkk. 2013. Peningkatan Kemampuan Pemecahan Masalah Dan Komunikasi Matematis Siswa Sekolah Menengah Pertama Melalui Model Pembelajaran Kooperatif Tipe Think-Pair-Share (TPS). Vol 1 number 2, April 2013

Junaryadi, Bambang. 2012. Pengembangan Perangkat Pembelajaran Matematika Model Kooperatif Tipe Two Stay Two Stray Dengan Pendekatan Konstruktivisme Untuk Meningkatkan Kemampuan Komunikasi Matematis Siswa. Vol 1 number 1, Juni 2012

Saraswati, In Diyah dkk. 2012. Penerapanpembelajarantwostay-Twostrayterhadap Kemampuan Pemahaman Konsep Dan Minat. Vol 1 number 1, Agustus 2012

Sumaryanta. 2015. Pedoman Penskoran. Vol 2 number 3

Ni'mah, A dan P. Dwijananti.2014. Penerapan Model Pembelajaran Think Pair Share (Tps) Dengan Metode Eksperimen Untuk Meningkatkan Hasil Belajar Dan Aktivitas Belajar Siswa Kelas Viii Mts. Nahdlatul Muslimin Kudus. Vol 3 number 2, Agustus 2014

Habibi, Ziyad dan Puput Wanarti Rusimamto. 2014. Pengaruh Model Pembelajaran Kooperatif Tipe Tsts (Two Stay Two Stray) Terhadap Hasil Belajar Siswa Pada Mata Pelajaran Teknik Elektronika Dasar Di Smk Negeri 1 Jetis Mojokerto. Vol 3 number 3,

Sugiyono, 2012. Metode Penelitian Kuantitatif, Kualitatif, dan R\&D. Bandung: Alfabeta

Saepuloh, Asep Rahmat. 2013 Penerapan Model Pembelajaran Sinektik Untuk Meningkatkan Kemampuan Representasi Dan Matematis Siswa SMP. Universitas Pendidikan Indonesia

Effendi, Leo Adhar. 2012. Pembelajaran Matematika dengan Metode Penemuan Terbimbing Untuk Meningkatkan Kemampuan Representasi dan Pemecahan Masalah Matematis Sisiwa SMP. Jurnal Penelitian Pendidikan Vol.13 number 2

Subandi, Sri dkk. 2014. Eksperimentasi Model Pembelajaan Kooperatif Tipe Two Stay Two Stray (TSTS) dan Think Pair Share (TPS) Pada Materi Persamaan dan Pertidaksamaan Linear Satu Variabel di Tinjau Dari Karakteristik Cara Berpikir Siswa Kelas VII SMP Negeri di Kabupaten Pacitan. Jurnal Elektonik Pembelajaran Matematika Vol 2 No 4 Hal 359-368 